Max-Planck-Institut für demografische Forschung

Max Planck Institute for Demographic Research

Konrad-Zuse-Strasse 1 - D-18057 Rostock · GERMANY

Tel +49 (0) 3812081 - 0; Fax +49 (0) 3812081 - 202;

http://www.demogr.mpg.de

MPIDR WORKING PAPER WP 2005-008

APRIL 2005

\title{
Becoming a parent in East Germany \\ during the 1990s. \\ The impact of personal considerations on the timing of entry to parenthood
}

Holger von der Lippe (vdlippe@ demogr.mpg.de)

Gunnar Andersson (andersson@ demogr.mpg.de)

This working paper has been approved for release by: Laura Bernardi (bernardi@ demogr.mpg.de) Head of the Independent Research Group on The Culture of Reproduction.

(C) Copyright is held by the authors.

Working papers of the Max Planck Institute for Demographic Research receive only limited review. Views or opinions expressed in working papers are attributable to the authors and do not necessarily reflect those of the Institute. 


\title{
Becoming a parent in East Germany during the 1990s.
}

\section{The impact of personal considerations on the timing of entry to parenthood.}

\begin{abstract}
This paper deals with psychological determinants of fertility differentials in East Germany in the 1990s. We test the explanatory and statistical power of psychological covariates in an event-history model of first-birth intensities together with other covariates. We show that different psychological covariates (wishes and fears, coping-styles, etc.) are important determinants of the transition to parenthood. A crucial finding is the existence of strong sex differentials in such impacts.
\end{abstract}

\author{
Holger von der Lippe \\ vdlippe@demogr.mpg.de \\ Gunnar Andersson \\ andersson@demogr.mpg.de
}

Max Planck Institute for Demographic Research, Rostock, Germany 


\section{Introduction}

Our study deviates from prior research on East German post-unification fertility (Roloff and Dorbritz 1999, Dorbritz 1997, Kreyenfeld 2001, 2003, Sackmann 1999) in that our particular aim is to investigate how different psychological factors related to people's personal considerations can contribute to the explanation of young adults' entry into parenthood in this context. We perceive a consensus in the literature that psychology indeed has something to say about fertility differentials in a population (Fawcett 1973, von Rosenstiel et al. 1986, Miller 1992, Miller and Pasta 1994). In a difficult societal situation, individual differences with respect to talents, desires, or abilities may be of particular importance for a full understanding and explanation of behavioral differences such as those in childbearing. So far, however, we do not know much about what factors of this kind that really matter and how they relate to each other and to other types of factors (Miller 1992: 269, Miller and Pasta 1994: 219). The development of a coherent and systematic body of knowledge on psychological determinants of childbearing behavior is still to come.

Our study takes a small step into that direction in exploiting unique in-depth information on personal considerations of a relatively small sample of men and women from Rostock. This allows us to gain insight into the significance of psychological variables for fertility behavior in the East German population and into the potential causal mechanisms of fertility differentials. After providing a brief sketch of the societal and demographic situation of the place of our study (Section 2), we present a suggestion for a linkage of psychological concepts and measurements with demographic theory (Sections 3 and 4). We carry out an event-history analysis of the transition to parenthood in East Germany in the 1990s of the cohort born in 1970/71 (Section 5) and discuss our findings, in particular the substantial sex differences of impacts that we observe (Sections 5 and 6).

\section{The demographic situation of Rostock and East Germany after German unification}

Our inquiry into the childbearing behavior of East Germans takes place in the city of Rostock in the province of Mecklenburg-West Pomerania (Mecklenburg-Vorpommern). With a population of about 200,000 inhabitants and located in the northeastern part of Germany (Figure 1), it is situated at a relative distance to Germany's main conurbations (with both Hamburg and Berlin a two-hour-drive away). The former economic motors of the Mecklenburg region and, especially, of Rostock were the shipyards, fish docks, and the international harbor. After German unification, these industries have reduced their activity. To some extent, the old characteristics of the region have been revived, with a stronger focus on its touristic, scenic, and agricultural Hanseatic charm. 
Figure 1. The location of Mecklenburg-West Pomerania and Rostock in Germany.

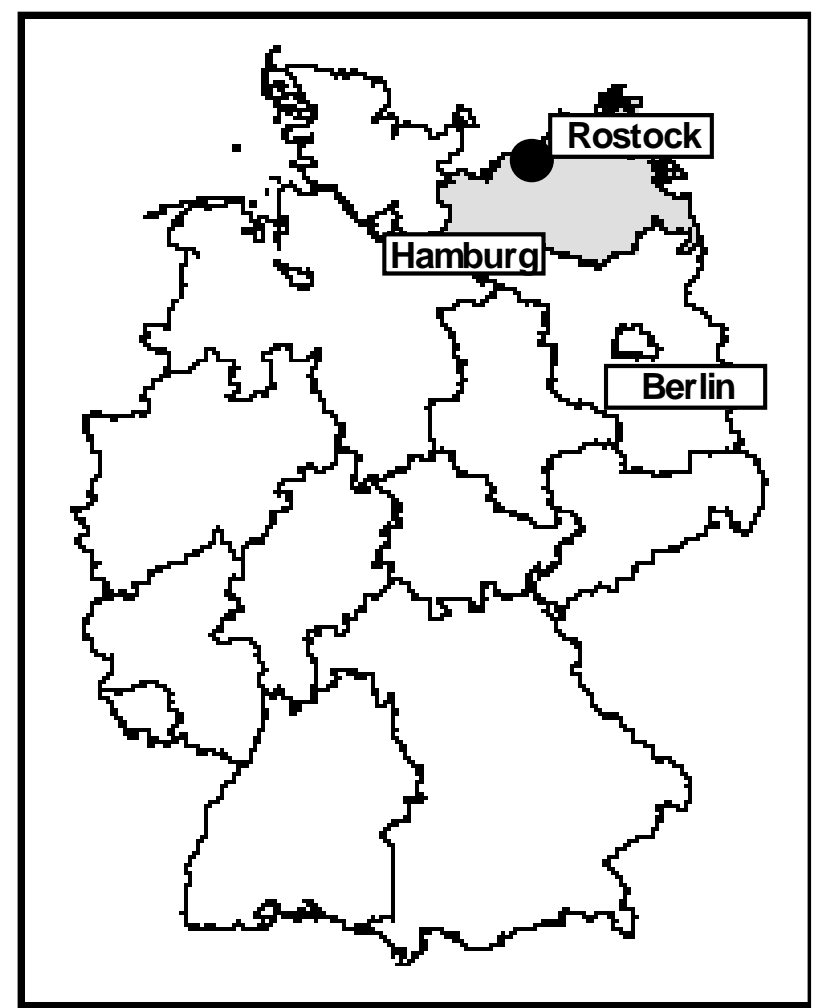

After the "Wende", Mecklenburg-West Pomerania (MWP) witnessed similar or worse demographic developments as the rest of the former GDR. It experienced a population drain due to emigration and a fall of birth rates. Population dropped from its highest level in more than 50 years in $1989(1,980,000)$ to its lowest level of the same time span 13 years after unification $(1,732,000$ in 2003, source: Statistisches Landesamt MWP).

The city of Rostock faced a similar fate. Its population declined from 248,000 in 1989, its highest level ever, to only 198,000 in 2003 (cf. Figure 2), which amounts to the level of 1970. (The fact that the surrounding district Bad Doberan gained about 25,000 inhabitants since unification reveals that this loss can in part be explained by suburbanization.) With such large-scale population shifts, any research on the social characteristics of people in this region needs to consider the possible impact of selective emigration from the area under study. (For an account of East-West German migration in the 1990s, see Heiland, 2004). 
Figure 2. Relative population losses of Mecklenburg-West Pomerania and Rostock, 1980-2001. (Source: Statistisches Bundesamt)

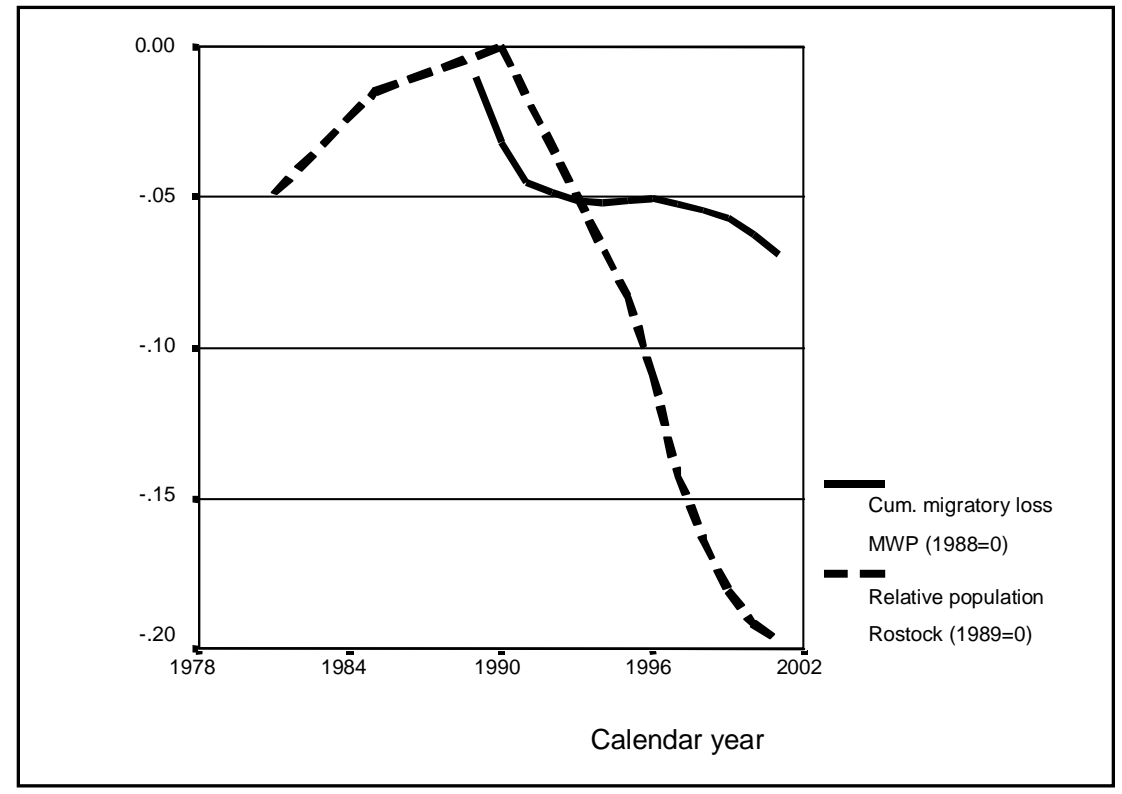

From an economic point of view, statistics reveal that Rostock and MWP fall slightly below the average of the former GDR provinces: With an unemployment rate of 18.2 percent in 2002, Rostock is slightly better off than its province (20.0 percent; this compares to 18.6 percent for the Eastern provinces as a whole). Regarding its economic output and density of work places, MWP enjoys a position that is comparable to the rest of the new federal states.

With regard to fertility, we observe a spectacular drop in the Total Fertility Rate (TFR) of MWP during the first half of the 1990s. It is followed by a recovery when the TFR of MWP also regains its position of being slightly higher than that of the rest of East Germany (Figure 3). ${ }^{1}$ In the next chapter, we summarize what we know so far about the causes of the East German fertility decline and about potential individual-level mechanisms of such development.

\footnotetext{
${ }^{1}$ During the socialist era, the three most northern districts of the GDR (which make up the present province of MWP) exhibited a slightly higher fertility level than the GDR as a whole (cf. Mehlan 1974: 2218, Figure 3, Dinkel 2000: 16).
} 
Figure 3. Total Fertility Rate of Mecklenburg-West Pomerania compared to that of East and West Germany, 1980-2000. (Sources: Statistisches Bundesamt and Statistisches Landesamt MWP)

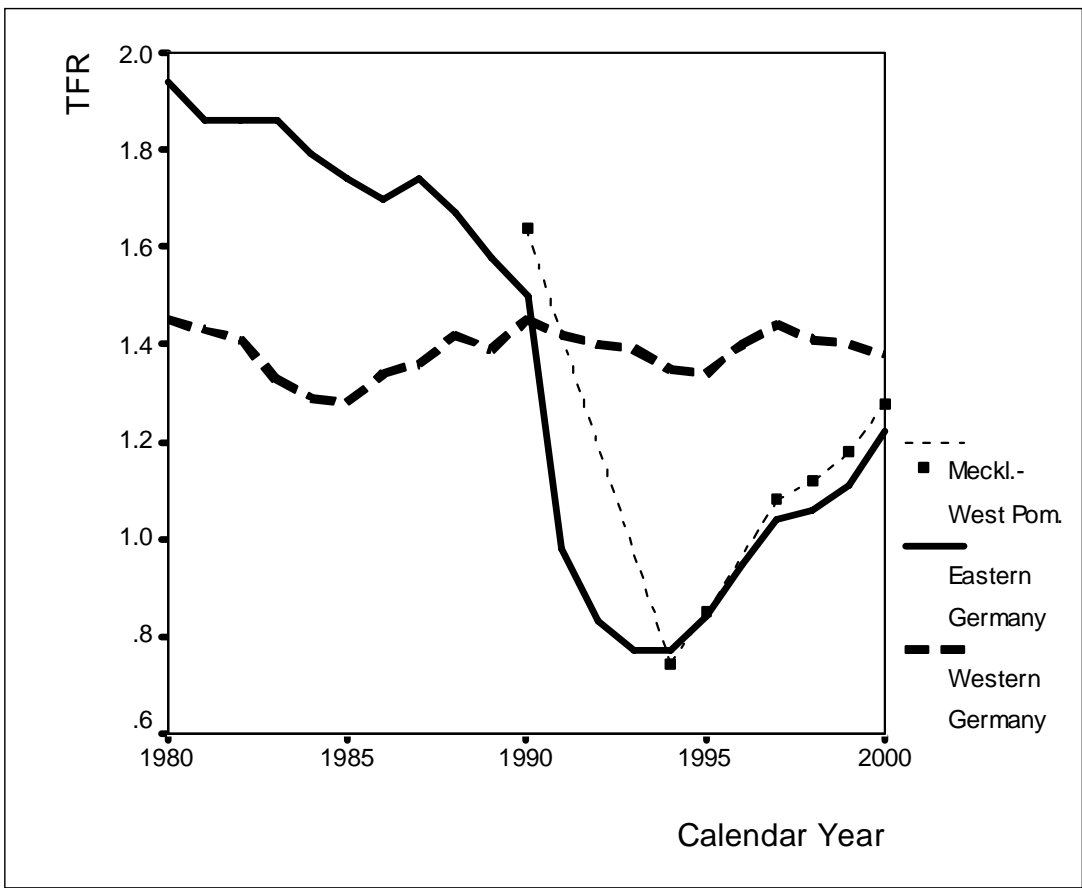

\section{Explaining fertility change in East Germany: Macro processes and individual behavior}

Looking at our study population, we are interested in patterns of fertility differentials between individuals, in particular differences in childbearing timing, and in an explanation of these patterns. We expect that when a formerly "natural matter of course" in terms of a highly standardized reproductive behavior in a socialist regime disintegrates, differences between people's psychological characteristics in terms of readiness and willingness for parenthood become more decisive for childbearing behavior (cf. Lesthaeghe and Vanderhoeft 2001).

From a sociological viewpoint, we are aware of some fundamental features of East German fertility change. We learn that more than a decade after unification many demographic rates seem to point to an adaptation to patterns in West Germany (such as the postponement of the entry age of parenthood), whereas other still develop in substantially different ways (such as the transition rates to second births and the share of out-of-wedlock births) (Kreyenfeld 2001, 2003). Very often, the discontinuation of financial incentives for early childbearing combined with large biographical uncertainties and strong postponement effects have been given as explanations for the declining fertility rates of East Germany (cf. Kohler 2000). 
However, several authors have also pointed out that "to a large extent, the question remains unsolved as to how the structural shift of fertility processes occurs after unification" (Sackmann 1999: 191; our translation). The application of individual-level (let alone psychological) data in order to address this question has been scarce. In recent years, we find not much more than the micro-economic analyses of the East German case by Lechner (2001) and the micro-sociological analyses of the impact of employment, educational attainment, and enrollment in education on the East German fertility by Klein et al. (1996) and Kreyenfeld (2001). These studies have been sufficiently reviewed by the literature (cf. Kreyenfeld 2003), and we do not repeat this here.

From beyond the context of East Germany, the important conceptual and empirical work on psychological determinants of childbearing by Miller (1992, 1994, 1995; Miller and Pasta 1994) is crucial for the direction of our own research. In his work, we find evidence for the value of a more sophisticated psychological approach to fertility research in general. (Empirically, this research is US-based.) From that we take the insight that a person's "own desire, attitudes, and beliefs are dominant [...] predictors" of childbearing intentions (Miller and Pasta 1994: 243) whereas the impact of these factors seems to vary substantially between women and men. Miller (1992) finds that childbearing motivation is, in part, determined by individual personality traits related to a tendency toward entering into attachments and performing care-taking.

However, also these studies suffer from weaknesses from the viewpoint of our focus. Neither of them applies psychological data in order to model prospectively actual childbearing behavior. Lechner (ibid.) intends to explain the amount of missed births in East Germany in the early 1990s in general, Kreyenfeld (ibid.) necessarily leaves out the analyses of psychological determinants of fertility, and Miller applies psychological data in order to explain people's childbearing motivations and their child-timing intentions by a cross-sectional approach. By contrast, our study aims at understanding psychological mechanisms that prospectively model the actual childbearing behavior of East German women and men in the 1990s. For this purpose, we draw on the reflections on the central relevance of a person's personal considerations for the decision to have a child as presented in a conceptual framework of demographic behavior provided by de Bruijn (1999). 


\section{Linking psychology to fertility: An integrative theoretical framework}

Since the 1970s psychologists have on a regular basis produced, paradoxically put, sporadic contributions to the study of demographic phenomena. Even so, the diagnosis still holds that there is a lack of systematic psychological research on fertility behavior. In order to link our psychological investigation as firmly as possible to demographic theory, we choose to relate it to the framework provided by the "foundation of demographic theory" as proposed by de Bruijn (1999). De Bruijn (ibid.: 3) introduces his theoretical framework by stating that "the accomplishments of demography in terms of descriptive abilities and statistical and mathematical achievements are not met by an equally sophisticated theoretical fundament"-which he traces back to a historic lack of interdisciplinary contributions to demography (cf. Caldwell 1982: 297). To improve this situation, he integrates concepts from various disciplines (such as psychology, sociology, demography, and anthropology) and adopts a micro perspective to describe individual behavior as it unfolds in an embedding social context.

We consider his framework useful for our study. It consists of a well defined description of fertility-related personal considerations. According to this framework, personal considerations are operationalizations of the individual choice process. Their contents and process are determined by a person's specific social context and by characteristics of his or her background. We will now elaborate on these concepts.

\subsection{Social context}

In de Bruijn's framework the social context of individual actors is conceptualized by institutions which he considers to be formal or informal bodies of society. They consist of "more or less coherent sets of rules which provide individuals not only with guidance for behavior in recurrent situations, but also with meanings to interpret the world and their own position in it" (de Bruijn, ibid.: 182; italics in original). That is, whatever we regard as relevant in the societal context "must be expressed in terms that bear relevance to the individual agents" (ibid.: 181). This cognitive-institutional approach implies rules that are objective in that they trigger fertility behavior without being affected substantially by various life-course processes at the individual level. They are subjective as well in that they are conceivable and perceived by the actor.

Let us examine this notion in more detail for the social institutions we consider relevant for the setup of our fertility study. We begin with the most basic demographic features of people, namely age and sex. These features are not determinants of behavior themselves, but shorthand terms of informal social institutions (ibid.: 149ff.). Examples of such institutions are the notions of (and rules for) "teenagers", "young women", "adult men", etc.. It is well-known that they bear different meanings from society to society. In the 
case of East Germany, we expect a different meaning of age when it comes to childbearing than for West Germany, because of the societal promotion of a much earlier transition to parenthood in life if we compare the two German regions. We suppose that the social rule of early childbirth has weakened during the 1990s and the impact of age will not be so unambiguous anymore as it has been during socialist times.

Another example on this line is the interaction of age with sex. We assume that different rules exist for men and women at different stages of their life course. Whilst for women the notion of a "biological clock" is typically strong (i.e., the knowledge that there are clear biological limits to childbearing), we can expect such guidelines to be weaker for men.

A standard variable in fertility studies is people's educational attainment. We include this information into our analysis because we assume that individuals share different general systems of meanings and life-goals according to their educational level. Highly educated people might be expected to attach a higher importance to their job career, but also to self-development and self-actualization. "Education must pay off' is a frequently heard rule in this context which may subjectively conflict with family formation. Bearing in mind the massive increase of retraining and schooling in new branches, which the East German population underwent after unification, we can expect a strong impact of diversifying educational levels on fertility.

\subsection{Personal considerations}

Whilst the former elements of the theoretical deliberations do not bear too much novelty for demographers or sociologists, the fertility framework of de Bruijn devotes extensive theoretical scrutiny to the concept of fertility choices. Choice processes are central to his framework. Herein, specific personal considerations determine people's fertility choices through defined settings of the personal problem space, of motivation processes, of personal control beliefs, and of styles of decision making (de Bruijn 1999: 92ff.). We explain these concepts in more detail and will then show how we derive operationalized covariates for our subsequent analysis (Section 5.2).

\section{2.a Problem space}

De Bruijn conceives of a person's problem space as the subjectively constructed and salient part of an individual's set of behavioral options and goals (ibid.: 189). Options and goals within a specific life domain are not thought to be objectively given, although they have clear links with social structure and individual background, but they take shape 
during a person's process of perception, evaluation, and selection. ${ }^{2}$ For our study, we can assume that an efficient way to attain an approximation of a respondent's problem space is to directly ask for general personal wishes and fears in life. We can assume that those people who come up with family-related wishes (like having a family) and fears (like losing one's family) even in times of societal upheaval may hold a more family and intimacy-oriented personal problem space than those who come up, for instance, with wishes for security or fears of economic loss. ${ }^{3}$ From the literature we know that a simple measurement of people's desire for a child (yes/no) does not lead to very useful predictions of their behavior (McClelland 1983, Noack and Østby 2001, cf. the discussion in Thomson and Hoem 1998) and, therefore, we prefer to rather deal with a measurement of general "motif for intimacy" (which may contain various goals) than with a purely child-related question. In Section 5 we explain measurement and hypotheses derived from this point in more detail.

\section{2.b Motivation processes}

De Bruijn's model of choice proposes a second element to an analysis of determinants of childbearing behavior, namely motivation processes. This refers to the structure, sources, and mechanisms of motivation, whereas the aforementioned options and goals refer to the content of motivation. We address the question of sources of motivation here.

In an influential paper, Ryan et al. (1996) review relevant findings and conclude that "cultural and interpersonal contexts influence what goals people emphasize and stress within their hierarchy of goals, and which ones are less salient or accentuated" (p. 20f.). They find that, for instance, people who grow up or live in an atmosphere of high control and low warmth are inhibited in their development of more autonomous and selfregulatory goals (ibid.). From these and other social psychological findings on motivation processes (see, for instance, Gollwitzer and Bargh 1996) we derive the relevance of not only asking people directly to what they aspire, but also to consider in how far they are provided with personal and social resources and which kind of social relations they experience. With the latter we also pay heed to recent research that shows that the perceived levels of social support and available resources influence virtually any kind of social behavior (Stroebe and Stroebe 1996).

\footnotetext{
2 Basically, it is possible that these processes are undertaken "rationally" by well-informed actors. Nevertheless, de Bruijn (ibid.) also allows for situations "that are characterized by complete ignorance of behavioral options, [...] where people do not have exactly circumscribed goals, [...] and where people rely on routines or standard rules for behavior and seemingly their only motivation is the 'normalcy' of such standards".

3 From the viewpoint of the psychology of motivation, family formation falls into the category of "reproduction of intimacy and affiliation" (Reis and Patrick 1996: 535f., cf. also Huinink 1995: 139 and Luhmann 1982: 183ff.).
} 
We expect variables from this field to have great relevance in times of societal upheaval when the availability of personal resources and relations may compensate for losses in the public or economic spheres. In how far this will impact on the transition to parenthood, is still fairly unexplored. ${ }^{4}$

\section{2.c Perceived action control}

Another element of de Bruijn's model for choice processes is people's perceived action control. This is, indeed, a component of many psychological theories of action (Rotter 1966, Bandura 1986, Ajzen 1991). The underlying idea is that the more people are convinced that they are capable of performing a certain action the higher is the propensity that they do so. De Bruijn states that "the perspective of (perceived) control over behavior is particularly relevant with respect to fertility behavior" (de Bruijn 1999: 191f.). It will be interesting to see what effect subjects' self-efficacy (as perceived action control has also been termed) has on their fertility behavior. A particular feeling of personal strength and optimism might have been required to dare entering parenthood in difficult times of social change where people could not rely on formerly provided institutional social security or formerly stable social bonds.

\section{2.d Decision styles}

The last element of de Bruijn's model of personal considerations consists in people's habitual decision styles. De Bruijn takes into consideration that people differ in the way in which they apply different strategies in their decision-making. He distinguishes whether they use a well-informed "rational" strategy, whether they rather follow personal heuristics, or whether they instead follow a norm driven routine behavior. While he leans on the rather analytical staging model of Janis and Man (1977), we will re-interpret this part of the choice process by examining coping styles instead. The psychological concept of coping styles is fairly similar to what de Bruijn describes as styles of decision-making, if one just relates them to strenuous or demanding situations. Coping is defined as an individual's flexible and problem-focused behavior when dealing with stress and demand. We assume that family-formation processes have many characteristics of such nature, especially if one considers the societal situation of East Germany in the 1990s. Thus, it appears worthwhile for us to examine the impact of people's typical behavior in critical situations on their actual childbearing behavior. Figure 4 provides a strongly abridged display of de Bruijn's framework in order to make clear where his concept of personal considerations is conceptually located.

\footnotetext{
${ }^{4}$ Recently, some conceptual and empirical developments with respect to "social capital" examine these relations in more detail (Lin 2001, Bühler and Fratczak 2004), but it is too early to derive conclusions from the demographic application of this relatively new branch of research.
} 


\subsection{Research questions}

In sum, we test the power of a set of psychological variables describing personal considerations in a choice process as explanatory covariates in a model of first-birth propensities. Our guiding questions are: What power do psychological covariates have when we relate them to social-structural covariates? Which psychological variables are particularly valuable, in general, and what sex differences appear, in particular? What conclusions can we draw on the individual-level mechanisms of childbearing decisions in East Germany in the 1990s, in particular, and on the ambiguous literature concerning the impact of personality traits on fertility, in general?

Figure 4. Strongly abridged draft of de Bruijn's fertility framework with a focus on the location of personal considerations (Source: de Bruijn 1999: 175).

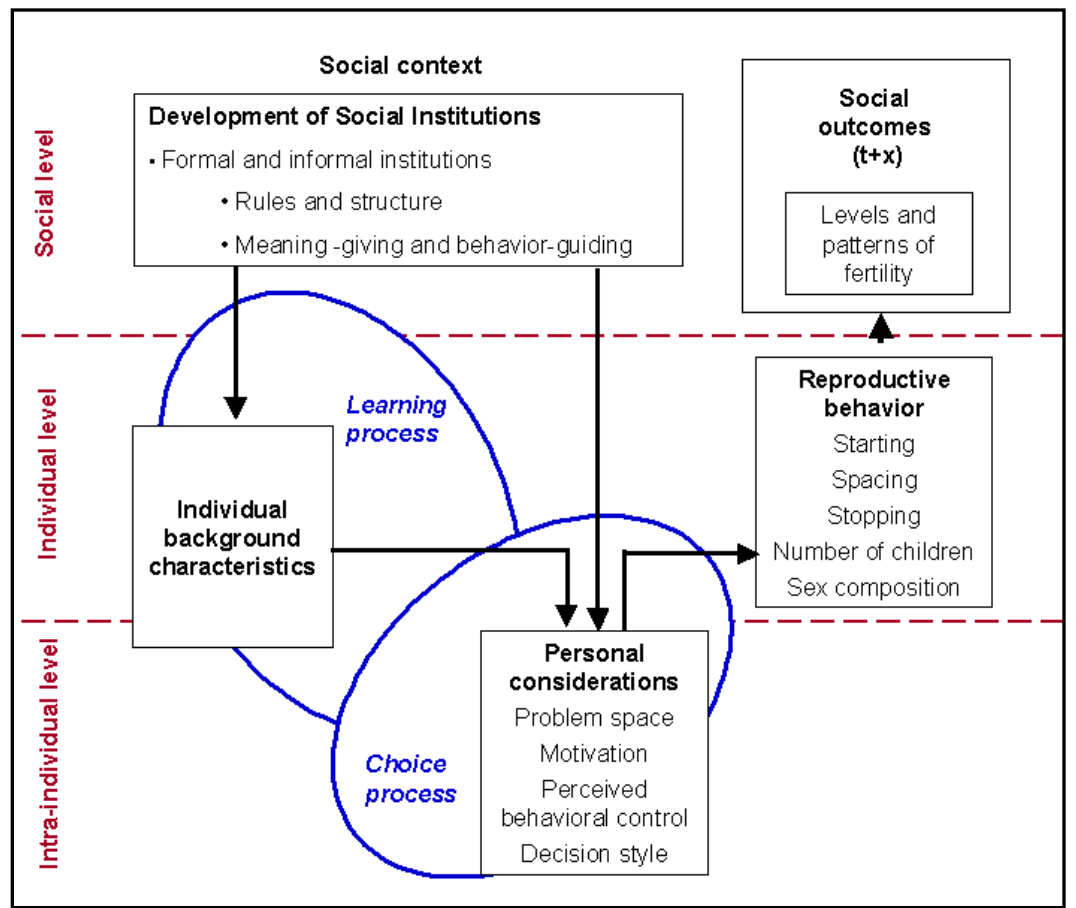




\section{A hazard regression of the transition to parenthood in Rostock, 1990-2003, incorporating psychological covariates}

We study the childbearing histories of slightly more than 200 young men and women of Rostock during 1990 to 2003. While acknowledging the very small size of our study sample, we apply an event-history analysis in order to capture the impacts of various factors on the observed transition rates to parenthood according to the theoretical framework from Section 4. We provide numerical estimations of the influence of psychological and other covariates on childbearing behavior. In each step, we calculate separate models for women and men.

\subsection{Data: The Rostock Longitudinal Study in its fourth decade}

The data for our empirical investigation stem from an extensive medical-psychological longitudinal survey conducted by the Institute for Medical Psychology of the University of Rostock. The Rostock Longitudinal Study (ROLS; Meyer-Probst and Teichmann 1984) commenced in 1970 with the purpose of investigating the life-long impact of biological, social, and psychological risk factors on human development. The initial sample consisted of 1,000 newborns and their mothers. It was collected in 1970/1971 (age $=0$ ) and then reduced to a core sample of 300 children who attended the Kinderkrippe (Kindergarten for the very young) in 1972 at age 2. Follow-up studies took place at ages $6(\mathrm{~N}=279), 10(\mathrm{~N}=268), 14(\mathrm{~N}=247), 20(\mathrm{~N}=199)$, and $25(\mathrm{~N}=212)$. Individuals were also followed when they had left Rostock.

From the standpoint of our study, German unification can be regarded as a very particular event because a great amount of data had been collected already before the "quasi-experiment" (Bronfenbrenner 1981) of societal change. The subjects of the sample entered adulthood at the time of unification and had to cope with the various challenges of a quickly changing labor market and education system. In general, the first period after German unification can be described as an orientation period (Zapf 1994). Some of the respondents opted for new vocational training; others migrated to other places in Germany and Europe (Reis et al. 1996).

A second favorable characteristic of the Rostock Longitudinal Study is given by the fact that its main focus of interest has shifted over the years to include more sociological and psychological items. It now provides a rich selection of interesting data for research on life-course transitions. Table 1 depicts the various waves of the survey. It also includes information on the interview-scheme that the first author performed in 2002/2003 in order to obtain the fertility history of the participants. We want to emphasize the fact that still, more than 30 years after the start of the study, an extraordinarily high share of 70 percent of the original sample can be contacted. 
Table 1. The Rostock Longitudinal Study, 1970-2003.

\begin{tabular}{rcccccccc}
\hline & $\mathbf{1}^{\text {st }}$ wave & $\mathbf{2}^{\text {nd }}$ wave & $\mathbf{3}^{\text {rd }}$ wave & $\mathbf{4}^{\text {th }}$ wave & $\mathbf{5}^{\text {th }}$ wave & $\mathbf{6}^{\text {th }}$ wave & $\mathbf{7}^{\text {th }}$ wave & $\begin{array}{c}\text { Phone } \\
\text { interviews }\end{array}$ \\
\hline Year & $1970 / 71$ & $1972 / 73$ & $1976 / 77$ & $1980 / 81$ & $1984 / 85$ & $1990 / 91$ & $1995 / 96$ & $2002 / 03$ \\
$\begin{array}{r}\text { Mean age } \\
\text { (subjects) }\end{array}$ & 0 & 2 & 6 & 10 & 14 & 20 & 25 & 32 \\
$\begin{array}{r}\text { N (subjects) } \\
\begin{array}{r}\text { percent of } \\
\mathbf{1 9 7 2} \text { sample }\end{array}\end{array}$ & 1000 & 294 & 279 & 268 & 247 & 199 & 212 & 206 \\
\hline
\end{tabular}

In an evaluation of the study-population characteristics, Reis (1997: 51; our translation) finds that "the development of the study sample follows the trend of the [whole] GDR" as exemplified by increasing salaries over time (age), increasing labor-force participation, etc. The only noteworthy deviation he observes is that it is the most "extreme" cases that have tended to drop out of the sample. He concludes that the ROLS data is still a highquality representative sample for studies of "normal" processes such as childbearing. Table 2 summarizes the basic socio-demographic features of the subjects. We see that by age 25 the typical participant of ROLS had finished education, was employed, lived with a partner, and was childless.

Table 2. Sample characteristics and measures from the $6^{\text {th }}$ and $7^{\text {th }}$ wave of ROLS.

\begin{tabular}{|c|c|c|}
\hline Variable & $1990 / 91$ & 1995/96 \\
\hline Mean age (years) & ca. 20 & ca. 25 \\
\hline \multicolumn{3}{|l|}{ Sex } \\
\hline Male & $96(48 \%)$ & $99(47 \%)$ \\
\hline Female & $103(52 \%)$ & $113(53 \%)$ \\
\hline \multicolumn{3}{|c|}{ Educational attainment (years in school) } \\
\hline Not finished school (7) & $4 \%$ & - \\
\hline Semi-skilled worker (8) & $2 \%$ & - \\
\hline Skilled worker $8^{\text {th }}$ grade $(8)$ & $4 \%$ & $5 \%$ \\
\hline Skilled worker $10^{\text {th }}$ grade $(10)$ & $58 \%$ & $71 \%$ \\
\hline Technical college (12) & $13 \%$ & - \\
\hline Abitur (high-school) (12) & $17 \%$ & $24 \%$ \\
\hline \multicolumn{3}{|l|}{ Occupation } \\
\hline Employed & $61 \%$ & $58 \%$ \\
\hline Self-employed & - & $3 \%$ \\
\hline Military/community service & $9 \%$ & $6 \%$ \\
\hline At school/college & $11 \%$ & $18 \%$ \\
\hline Unemployed & $6 \%$ & $4 \%$ \\
\hline Other/non-classified & $2 \%$ & $6 \%$ \\
\hline \multicolumn{3}{|l|}{ Living arrangement } \\
\hline With parent(s) & $77 \%$ & $14 \%$ \\
\hline Alone, own household & $10 \%$ & $23 \%$ \\
\hline With partner, own household & $13 \%$ & $54 \%$ \\
\hline Other & - & $8 \%$ \\
\hline \multicolumn{3}{|l|}{ Has a steady relationship } \\
\hline Yes & $59 \%$ & $76 \%$ \\
\hline \multicolumn{3}{|l|}{ Has a child } \\
\hline Yes & $4.5 \%$ & $16 \%$ \\
\hline
\end{tabular}


For the purpose of the statistical analysis of birth risks, we select a set of psychological and other measures from the sixth and seventh wave of the study in order to explain childbearing behavior in subsequent years. Table 3 shows that altogether 111 first and 30 second births had occurred by the date of the phone interviews to the subjects of our analysis in 2002/03, most of them to women. (Three reported third births are not provided in the table.) In this paper we report on observed transition patterns to a first birth.

Table 3. Observed births in the ROLS.

\begin{tabular}{crrr}
\hline & $\begin{array}{r}1984 / 85-1995 / 96 \\
\text { age approx. } 14-25\end{array}$ & $\begin{array}{r}1995 / 96-2002 / 03 \\
\text { age approx. 25-32 }\end{array}$ & Total \\
\hline $\begin{array}{c}\text { Men } \\
1^{\text {st }} \text { births }\end{array}$ & & & \\
$2^{\text {nd }}$ births & 6 & 33 & 39 \\
Women & 3 & 4 & 7 \\
$1^{\text {st }}$ births & 28 & 44 & 72 \\
$2^{\text {nd }}$ births & 13 & 10 & 23 \\
Total & & & \\
$1^{\text {st }}$ births & 34 & 77 & 30 \\
$2^{\text {nd }}$ births & 16 & 14 & \\
\hline
\end{tabular}

\subsection{Methods and measures: Hazard regression, covariates, and hypotheses}

\subsubsection{The model}

We apply a hazard regression (event-history analysis) to model the risk of childbirth to childless individuals over time. A risk (hazard) is defined as the individual probability of experiencing an event at time $t$ under the condition that it has not yet been experienced. For transitions to parenthood, we first need to define a risk population of childless men and women at ages 15 and above. Individuals leave this study population either due to a first birth or censoring. This method accounts for the appropriate time dependency of the process under investigation. The transition rate model is represented mathematically by

$$
\ln \mu_{i}(t)=y(t)+\sum_{k} \beta_{k} x_{i k}+\sum_{l} \lambda_{l} z_{i l}(t)
$$

where $\mu_{i}(t)$ is the hazard of occurrence of entry to parenthood at time $t$ for individual $i$, $y(t)$ captures a baseline hazard that is a function of age, $x_{k}$ is the $k$ th time constant covariate, and $z_{l}$ is the $l$ th time-varying covariate with $\beta$ and $\lambda$ as the corresponding regression parameters.

In the following two sub-sections, we describe the variables that we use in the statistical modeling, and spend some consideration on how we constructed these measures. In addition, we elaborate on hypotheses of the expected impact of covariates. 


\subsubsection{Social-structural covariates}

The theoretical model from Section 4 suggests that certain characteristics of an individual's social context guide individual behavior and give meaning to people's action by assigning them different types of social status. The first variable of this kind is an individual's age, which we include as the basic time factor. In our study, it also picks up effects of calendar time. This is because the Rostock sample is based on a single cohort. In our case, age 20 corresponds to the calendar year 1990/1991, age 25 to 1995/1996, etc. Thus we are not able to disentangle age effects from period effects. The second basic demographic variable depicts the time-constant sex of any individual. In many cases, we are interested in sex differentials in the impact of other explanatory variables on childbearing. Thus we calculate separate models for men and women, respectively, rather than use sex merely as an independent variable.

We apply two additional measures to approximate people's social status. First, we use the current educational attainment in years of completed education as a time-varying characteristic. Secondly, we use a measure of the occupational position of the parents of the subjects when they were 14. The latter measure is derived from an ordinal rating that assigns a value of 1 to an unskilled worker and a value of 6 to a parent with a top managerial position and academic education. We add the values of both parents so that the final variable sums up to a maximum value of 12 . (In case of missing values, we assume the average value of the population.) We derive a slightly right-skewed distribution with a median value of 6 and a mean of 7.3. It is well documented that people with a high educational attainment tend to differ in their childbearing behavior from people with a low level of education (e.g., Huinink 1995). To a large extent, this effect stems from the fact that a longer enrollment in education as such is temporarily incompatible with childbearing. In addition, those who invest more time and effort in education and their career will postpone childbearing until they are well settled in the work sphere. People with a stronger career orientation will probably not belong to the early child bearers. Thus, we expect that a higher level of own education is related to a postponement of entry to parenthood. The application of such rules can partly depend on the socialization in the family of origin. This is why we consider the occupational position of the parents as well.

\subsubsection{Covariates of subjects' personal considerations}

The main purpose of this study is to examine the role which people's personal considerations play for the transition to parenthood. For these considerations we have created a variety of different variables that describe the aforementioned elements of the 
choice-of-parenthood process. We group these variables into four clusters which correspond with those of the theoretical outline of Section 4.

\subsection{3.a Approximating the personal problem space: Desire for intimate relations and fear of losing intimate relations}

The first group of variables has been constructed to depict an approximation of a person's personal problem space (see Section 4). We build variables which describe the expressed relevance of intimate relations for the respondents from their answers to open questions in an interview setting about "the most important desires for and fears from life". From these answers we construct two variables that depict respectively the overall desire for intimacy in life and the overall fear from losing intimacy. For the former, we summarize answers that contain expressions like "I want a family of my own", "a longterm relationship", or "family harmony" and create a sum score of such expressions, with one point per expression. In this sample, it ranges from 0 to 3 . We use the same procedure for the latter variable and describe the overall fear of losing intimate relationships and affiliation from a parallel question on the "most important fears in life". Scoring answers are, for example, expressions of fear of "staying alone/having no mate", "loss of family harmony", and "loss of meaning". Again, the empirical range of this score is from 0 to 3 . Analogous measures are available from the waves at ages 20 and 25 .

One may expect that variables for wishes for and fears of losing intimacy are highly interrelated, but we find only moderate correlation coefficients around 0.30. Table 4 depicts this and also the low stability of these wishes and fears over a five-year period. Answers seem to change with time and might depend strongly on people's current situation or mood.

Table 4. Inter- and intra-correlation of wish for intimacy and fear of losing it.

\begin{tabular}{rrrrr}
\hline & wish at age 20 & wish at age 25 & fear at age 20 & fear at age 25 \\
\hline wish at age 20 & 1 & & & \\
wish at age 25 & 0.083 & 1 & & \\
fear at age 20 & 0.373 & 0.104 & 1 & \\
fear at age 25 & 0.105 & 0.223 & 0.082 & 1 \\
\hline
\end{tabular}

$\mathrm{p}<0.05$ in bold face

We do not expect very strong results for these variables because of their instability over time. As a tendency, however, people who express at least some desire for intimacy or some fear of losing it, may have an earlier start of childbearing than people with a zero value in this covariate because they have at least some periods of stronger orientation toward starting a family. 


\subsection{3.b Specific sources for motivational processes: Personal resources and social relations}

As we already introduced in Section 4, the level of perceived social support and personal resources will serve to model de Bruijn's notion of social sources of motivation. We include in the analysis four covariates of perceived resources. We have Likert-scale ratings ${ }^{5}$ from both waves (1990 and 1995) on the extent to which subjects feel supported and backed by (a) their own knowledge and skills, (b) their family, (c) their partner, and (d) their friends when thinking about their current life and future. These ratings range from 1 (low level of perceived support) to 6 (high level of perceived support). For the perceived support of a partner we construct an additional category for subjects who do not have a partner at the time of the interview. Correlations between the covariates of this type remain consistently weak (below 0.20) and do not require further consideration.

A related group of variables depicts the perceived quality of respondents' social relations. They are not limited to issues of help by others and social support, but also depict non-instrumental, emotional-affective aspects of social life. For example, they are based on information on the extent to which subjects have contacts with others, are able to exchange views, and experience reciprocity in their interactions. Again, we focus on the role of friends and family, respectively, so that one variable for each group of relations is included in the model. We have again Likert-scale self-ratings on the perceived emotional closeness with friends and family. Also these covariates are not substantially interrelated $(r<0.20)$. However, we find considerable correlation between the variables that measure resources from and quality of relations with friends. Here, correlation coefficients are significant and assume sometimes high values $(\mathrm{r}=0.29$ at age 20; $r=0.79$ at age 25). This tells us that a peer-related resource consists mainly in the emotional quality of this friendship-and vice versa. We need to keep potential collinearity in mind for the forthcoming analyses.

With regard to hypotheses, we expect that people with high interpersonal resources are also better equipped to master the transition to parenthood and, thus, experience it earlier in their lives. Additionally, people with good social relations (especially, with their families) may set up their own families earlier than others because of the good role model they experience (for the effect of social learning, cf. Bandura 1986, Bernardi 2003; for effects of instrumental support, cf. Bühler and Fratczak 2004).

\footnotetext{
${ }^{5}$ Likert-scale questions ask respondents to choose from a set of three or more possible answers to a question (forced choice).
} 


\subsection{3.c Perceived action control: General optimism}

For this section, we only add one, admittedly broad, variable that is based on the person's overall rating concerning his or her general optimism in life. This covariate describes to what extent respondents are convinced that they can achieve their goals in life and how much self-efficacy they experience. Whilst not being very refined, we avail ourselves of parallel data at ages 20 and 25. These self-ratings consist of a Likert scale ranging from not optimistic at all (1) to highly optimistic (5). We expect that a strong degree of personal optimism is required for young East Germans in order to establish an own family during the 1990s, as many shortcomings and hassles of the unfavorable societal situation had to be overcome by people's own initiative.

\subsection{3.d Coping styles}

We attain a measurement of people's cognitive and conative patterns in decisionrequiring situations, that is of their coping styles (see Section 4). These patterns are measured by a standard self-rating inventory of coping styles ("Stress-VerarbeitungsFragebogen", see Janke et al. 1997) and were gathered from respondents at the interview wave at age 20. By means of a factor analysis (principal components, Varimax rotation), we distinguish four non-correlated coping styles based on the inventory of 114 different response items that respondents could choose to rate the extent to which they react to stress or demand by, for instance, getting angry, asking others for advice, or hiding away in work. These factors are described in Table 5.

Table 5. Factors of personal coping styles as derived from stress inventory.

\begin{tabular}{ll}
\hline Factor name & Description \\
\hline Withdrawal & $\begin{array}{l}\text { Coping by escape. Subjects with high scores tend to withdraw from social } \\
\text { contact and to flee from stressful demand. They also self-accuse and give up } \\
\text { more frequently. }\end{array}$ \\
Control & $\begin{array}{l}\text { Coping by control. Subjects with high scores perform a direct, tackling and } \\
\text { straightforward strategy to obtain control over and to react self-responsibly } \\
\text { toward a stressful demand. }\end{array}$ \\
Rationalization & $\begin{array}{l}\text { Coping by rationalization. Subjects with high scores react to stress and } \\
\text { demand by persuading themselves that such a situation is unimportant, not } \\
\text { really demanding, or not addressing it at all. }\end{array}$ \\
& $\begin{array}{l}\text { Coping by alternatives. Subjects with high scores prefer evasion and } \\
\text { diversion when being confronted with stress and demands. They prefer } \\
\text { turning toward easier alternatives instead. }\end{array}$ \\
\hline
\end{tabular}

Assuming that parenthood now and then is a burdensome and demanding endeavor, we assume that people with a high value in control are more prone to realize parenthood early than others. Those who have more avoiding coping styles arguably look for easier 
alternatives instead, in particular when facing the potential hardships of parenthood in societal difficult times.

\subsection{Results I: Social structure, personal considerations, and the transition to parenthood}

We begin with the analysis of the transition to first-time parenthood by describing the impact of age, sex, and educational characteristics (Section 5.3.1). This provides a starting point for the analysis, and allows us to detect whether first-birth patterns in the sample correspond to those observed elsewhere for East Germany. Due to the small sample size, we need to be reassured that the basic patterns of the childbearing dynamics of the subjects do not deviate from standard patterns. In Section 5.3.2, we introduce various models in order to investigate the impact of the different covariates describing personal considerations. Data on these characteristics were collected only at ages 20 and 25. That is, we restrict the models to childbearing propensities at ages 20 to 32 and will not study the childbearing of teenagers in that section.

\subsubsection{Some baselines}

To commence the empirical analyses, we examine how subjects' risk of first birth changes with age (Figure 5). We find that it increases from very low levels at ages below 20. For men, the risk is lower than for women during the whole age frame of our study, but tends to catch up with that of women at the higher ages. This reflects that men normally become parents at higher ages than women. The age pattern also reflects effects of calendar time: The increase in first-birth intensities at the upper ages coincides with an increase in fertility in East Germany towards the very end of the study period.

Figure 5. First-birth intensities, by age, for women and men.

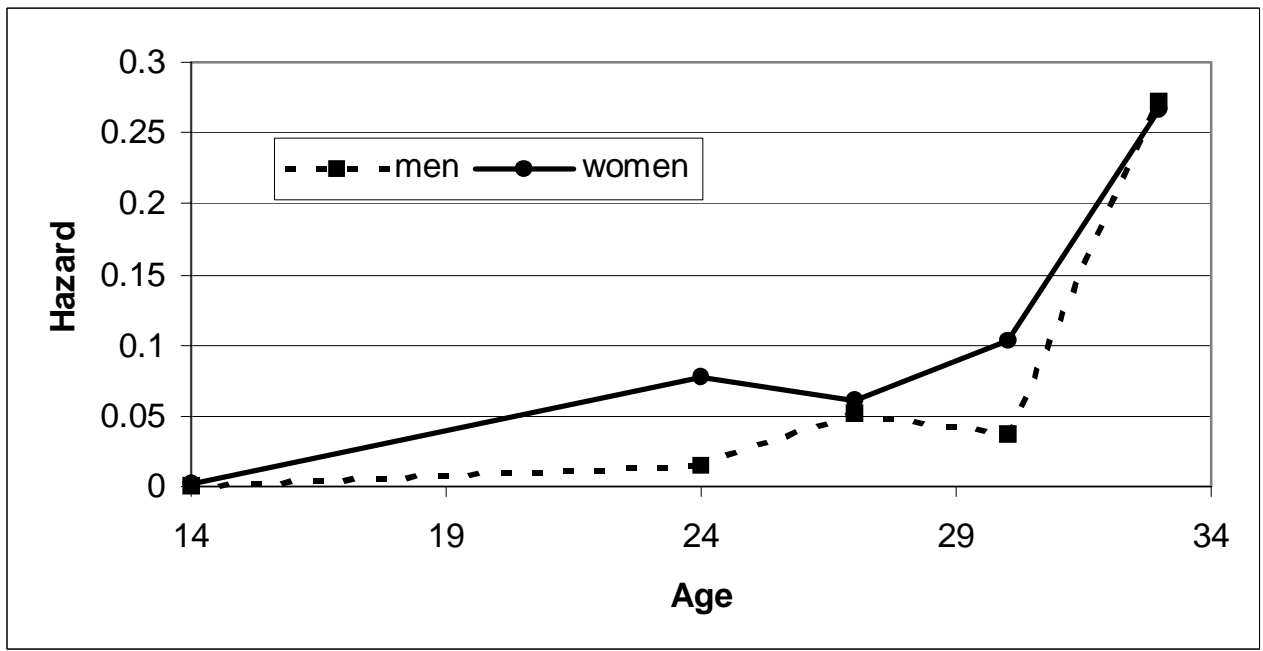


Next we include the two socio-economic variables into the model and obtain significantly positive effects of a low education of female subjects and a low occupational status of their parents on entry into motherhood (Table 6). These effects appear to be less clear for men. For them, it seems that the occupation of their parents has a similar impact as for women, while the effect of their own current educational attainment fails to reach significance at the levels we use $(1,5$, or 10 percent).

Table 6. Relative risk of first birth, by educational variables, controlled for age.

\begin{tabular}{|c|c|c|c|c|}
\hline & Men & & omen & \\
\hline & coeff. & $p$ & coeff. & $\bar{p}$ \\
\hline \multicolumn{2}{|c|}{$\begin{array}{l}\text { Model improvement by including } \\
\text { educational variables }\end{array}$} & .307 & & .000 \\
\hline \multicolumn{5}{|c|}{ Individuals' current education } \\
\hline low & 2.42 & .21 & 6.11 & .01 \\
\hline average & 1 & ref. & 1 & ref. \\
\hline high & 1.75 & .24 & 0.57 & .10 \\
\hline \multicolumn{5}{|c|}{ Parents' occupational status } \\
\hline low & 1.94 & .13 & 1.80 & .04 \\
\hline average & 1 & ref. & 1 & ref. \\
\hline high & 1.22 & .69 & 1.03 & .93 \\
\hline
\end{tabular}

Note: Significance at 10-percent level indicated by bold face.

\subsubsection{The impact of personal considerations on first-birth intensities}

In this section, we analyze the impact of the variables of the four clusters of personal considerations on first-birth risks at ages 20 and above. The main purpose of the section is to single out those psycho-social variables within each cluster that bear evidence of their impact on childbearing behavior before controlling for other covariates. We present models for men and women separately throughout the analysis. In our selection procedure, we focus on the statistical significance of effects, but due to the small size of the data we also try to interpret non-significant patterns. In a study such as ours, we do not want to be bounded by significance levels alone, but must leave some room also for tentative interpretation. We will as well keep an eye on potential collinear ties among the covariates in this section. A final integrative model which includes as many covariates as reasonable plus interpretation and discussion is provided in Section 5.4. 


\subsection{2.a The impact of personal wishes and fears}

The results for the first cluster of psychological covariates, namely personal wishes and fears in life, are given in Table 7. The model improvement when adding the entire group of variables to a basic model with only age is not significant when we estimate models separately for men and women. The p-values of the Log Likelihood Ratio Tests (LLRT) are 0.40 and 0.52 , respectively. As we expected, the impact of expressed wishes and fears remains weak.

Looking at patterns, we find that the impact of a high desire for intimacy on first-birth risks apparently is slightly (that is, non-significantly) negative and that a high fear of losing intimacy holds a positive effect (also non-significant). The weak patterns for the desire-variable are similar for men and women, whereas the positive impact of the fearvariable seems to be clearer for men than for women. The former counter-intuitive finding that a desire for intimate relationships does not increase the risk of first birth is rather surprising, but corresponds to our previous analyses of childbearing at ages below 25 (von der Lippe et al. 2002). The latter effect, in contrast, points in the expected direction saying that those who are explicitly afraid of losing intimate relations tend to be more inclined to reproduce themselves by childbirth earlier. Despite lack of significance, we decide to keep both variables, which are only moderately correlated with each other, for further examination in a more inclusive model.

Table 7. Relative risk of first birth. Impact of desires and fears, controlled for age.

\begin{tabular}{|c|c|c|c|c|}
\hline & Men & & Women & \\
\hline & coeff. & $p$ & coeff. & $p$ \\
\hline $\begin{array}{l}\text { Model improvement by variables } \\
\text { (LLRT p-value) }\end{array}$ & & .401 & & .520 \\
\hline \multicolumn{5}{|l|}{ Desire for intimacy } \\
\hline low & 1 & ref. & 1 & ref. \\
\hline high & 0.69 & .36 & 0.77 & .35 \\
\hline \multicolumn{5}{|l|}{ Fear of losing intimacy } \\
\hline low & 1 & ref. & 1 & ref. \\
\hline high & 1.63 & .23 & 1.28 & .41 \\
\hline
\end{tabular}

\subsection{2.b The impact of processes of social motivation}

The inclusion of four scales on perceived individual resources increases the fit of the basic model with only age substantially for men $(\mathrm{p}=0.06)$, whereas this is not the case for women $(\mathrm{p}=0.27)$. However, none of the single variables achieves results at an adequate level of significance by themselves (Table 8 ). 
Table 8. Relative risks of first birth. Impact of personal resources, controlled for age.

\begin{tabular}{crrrr}
\hline & Men & \multicolumn{3}{c}{ Women } \\
\hline & coeff. & $p$ & coeff. & $p$ \\
Model improvement by & & & & \\
variables (LLRT p-value) & & .058 & & .271 \\
Resources self & & & & \\
low & & & & \\
average & 1.61 & .74 & 0.81 & .76 \\
high & 2.35 & .54 & 0.67 & .45 \\
low & & & & \\
average & 1 & ref. & 1 & ref. \\
high & 1.39 & .95 & 2.37 & .41 \\
Resources family & 1.10 & .83 & 0.80 & .43 \\
no partner & & & & \\
low & 1 & ref. & 1 & ref. \\
high & 0.77 & .96 & 0.87 & .87 \\
Resources partner & 2.75 & .85 & 1.65 & .59 \\
low & & & & \\
average & 1 & ref. & 1 & ref. \\
\& high & 0.95 & .92 & 0.81 & .47 \\
Resources peers & & & & \\
\hline
\end{tabular}

Note: Significance at 10-percent level indicated by bold face.

When examining patterns of (non-significant) impacts, we find that different types of personal resources seem to have different impacts on first-birth intensities and that some of these tendencies differ between women and men. Whilst the resources from the family and from friends appear, all in all, rather unclear, it seems that the impact of self-centered resources appears to be quite the opposite for women and men. Men who report to feel strongly equipped by own skills and knowledge tend to become fathers earlier than others, whereas women with such properties rather become mothers later.

The effect of a well-functioning partnership indicates an expected relation. Particularly for men to have good resources from a partnership seems to be positively related to the transition to parenthood. Interestingly, to have a non-supportive partnership seems to be less favorable for a transition to parenthood than not having a partner at all. We decide to exclude the second and the forth resource variable from further consideration and will resume the test for the other two in the subsequent integration procedure (Section 5.4).

We also test two scales on the perceived quality of social relations in a basic model (Table 9). This procedure does not yield a significantly better fit. However we find an indication of some relevance for women but not for men. For women, a good quality of social relations with their family of origin as well as with their peers appears to decrease somewhat their transition risk. Since the difference to the absence of effects for men is 
quite interesting and the finding contradicts the hypotheses, we decide to follow up on these results in the further steps (Section 5.4).

Table 9. Relative risks of first birth. Impact of the quality of social relations, controlled for age.

\begin{tabular}{|c|c|c|c|c|}
\hline & Men & & Iomen & \\
\hline & coeff. & $p$ & coeff. & p. \\
\hline $\begin{array}{l}\text { Model improvement by variables } \\
\text { (LLRT p-value) }\end{array}$ & & .969 & & .147 \\
\hline \multicolumn{5}{|l|}{ Quality of relations to family of origin } \\
\hline low & 1 & ref. & 1 & ref. \\
\hline average \& high & 0.92 & .82 & 0.72 & .19 \\
\hline \multicolumn{5}{|c|}{ Quality of relations to peers and friends } \\
\hline low & 1 & ref. & 1 & ref. \\
\hline average \& high & 1.02 & .96 & 0.76 & .26 \\
\hline
\end{tabular}

\subsection{2.c The impact of general action control (optimism)}

The simple covariate capturing the general personal optimism in life, which we interpreted as an approximation to self-efficacy and general action control, turns out to have a strong significant impact on the first-birth risk, particularly that of men. Higher levels of personal optimism increase the risk of entry to parenthood for men, whereas the relative risk of women seems to peak at an average level of optimism (Table 10). Since we find that optimism is somewhat correlated with many other covariates (see Table 12), we decide to examine these initial findings in more detail in Section 5.4.

Table 10. Relative risks of first birth. Impact of personal optimism, controlled for age.

\begin{tabular}{lrrrr}
\hline & Men & & Women & \\
& coeff. & $p$ & coeff. & $p$ \\
Model improvement by variables & & & & \\
$\begin{array}{l}\text { (LLRT p-value) } \\
\text { Personal optimism }\end{array}$ & & .118 & & .092 \\
$\quad$ low & & & & \\
$\quad$ average & 1 & ref. & 1 & ref. \\
high & 2.18 & .16 & 1.60 & .22 \\
& 2.91 & .07 & 0.84 & .70 \\
\hline
\end{tabular}

Note: Significance at 10 -percent level indicated by bold face. 


\subsection{2.d The impact of personal coping styles}

Finally, the personal style of dealing with stress and demands does not increase, at first glance, the overall fit of the basic first-birth model (LLRT: $p>0.20$ ). However, we find two single significant effects for men and one significant effect for women (Table 11).

Men's coping style "withdrawal" is clearly negatively related to first-birth risks; habitual escapers have a reduced risk of transition to fatherhood as compared to other people. The women of the study sample, by contrast, display a pattern in this variable that rather suggests an increased risk of childbirth for higher values of withdrawal from problems. Whilst we find no effects for coping by "control", women who are strong "rationalizers" seem to have a significantly higher first-birth risk (no effect for men). Finally, the habitual easy-alternative seekers have a lower risk of first birth, and this applies to both women and men. For further modeling (Section 5.4), we thus focus on the impact of coping by withdrawal, rationalization, and alternatives and leave control aside.

Table 11. Relative risk of first birth. Impact of coping styles, controlled for age.

\begin{tabular}{crrrr}
\hline & Men & \multicolumn{3}{c}{ Women } \\
\hline & coeff. & $p$ & coeff. & $p$ \\
& & & & \\
Model improvement by coping- & & .212 & & .467 \\
styles (LLRT-value) & & & & \\
Coping by withdrawal & & & & \\
low & & & & \\
average & 1 & ref. & 1 & ref. \\
high & 0.49 & .12 & 1.75 & .12 \\
low & 0.17 & .05 & 1.58 & .38 \\
average & & & & \\
high & 1 & ref. & 1 & ref. \\
Coping by control & 1.24 & .66 & 1.21 & .64 \\
low & 0.94 & .96 & 1.48 & .42 \\
average & & & & \\
high & 1 & ref. & 1 & ref. \\
Coping by rationalization & 0.90 & .66 & 1.28 & .53 \\
low & 0.91 & .54 & 2.02 & .09 \\
Coping by alternatives & & & & \\
lowerage & 1 & ref. & 1 & ref. \\
high & $\mathbf{0 . 3 8}$ & .10 & 0.94 & .72 \\
& 0.66 & .56 & 0.56 & .28 \\
\hline
\end{tabular}

Note: Significance at 10-percent level indicated by bold face.

\subsection{Results II: An integrated model}

In order to bring the results together and to reveal potential ties among the covariates, we estimate two final integrative models on the first-birth transitions of young 
Rostockers. In a first model, we include all covariates of personal considerations which we found to be relevant in Section 5.3.2 (Model I). Then, we calculate their effects as they appear when we control also for educational covariates (Model II). A model with only educational covariates was presented in Section 5.3.1, Table 6. Note some particularities that we face in our model building. First, the small sample size can lead to an over-specification of our model if we try to introduce too many explanatory variables. A model based on too few events and too many covariates will largely result in insignificant estimates. In this case, we limit the number of included covariates by the initial screening of Section 5.3.2. Furthermore, we highlight the significance of estimated relative risks in our final models (Table 13) at four different probability levels: 1, 5, 10, and 30 percent. The latter figure is very high, but allows us to discuss patterns that appear informative, believing that a larger data set would have provided more favorable significance estimates (cf. Spielauer and Houle 2004).

We also need to pay attention to potential collinear ties among the covariates. Therefore, we first display correlations between the relevant covariates, in order to better understand the shifting of estimates and significance levels between models. Table 12 provides these correlation coefficients. Note that we only show the highest correlations we find between two variables as calculated at ages 20 and 25 .

Table 12. Highest observed correlations between relevant covariates for men and women aged 20 and 25 (only correlations with $p<0.20$ in display).

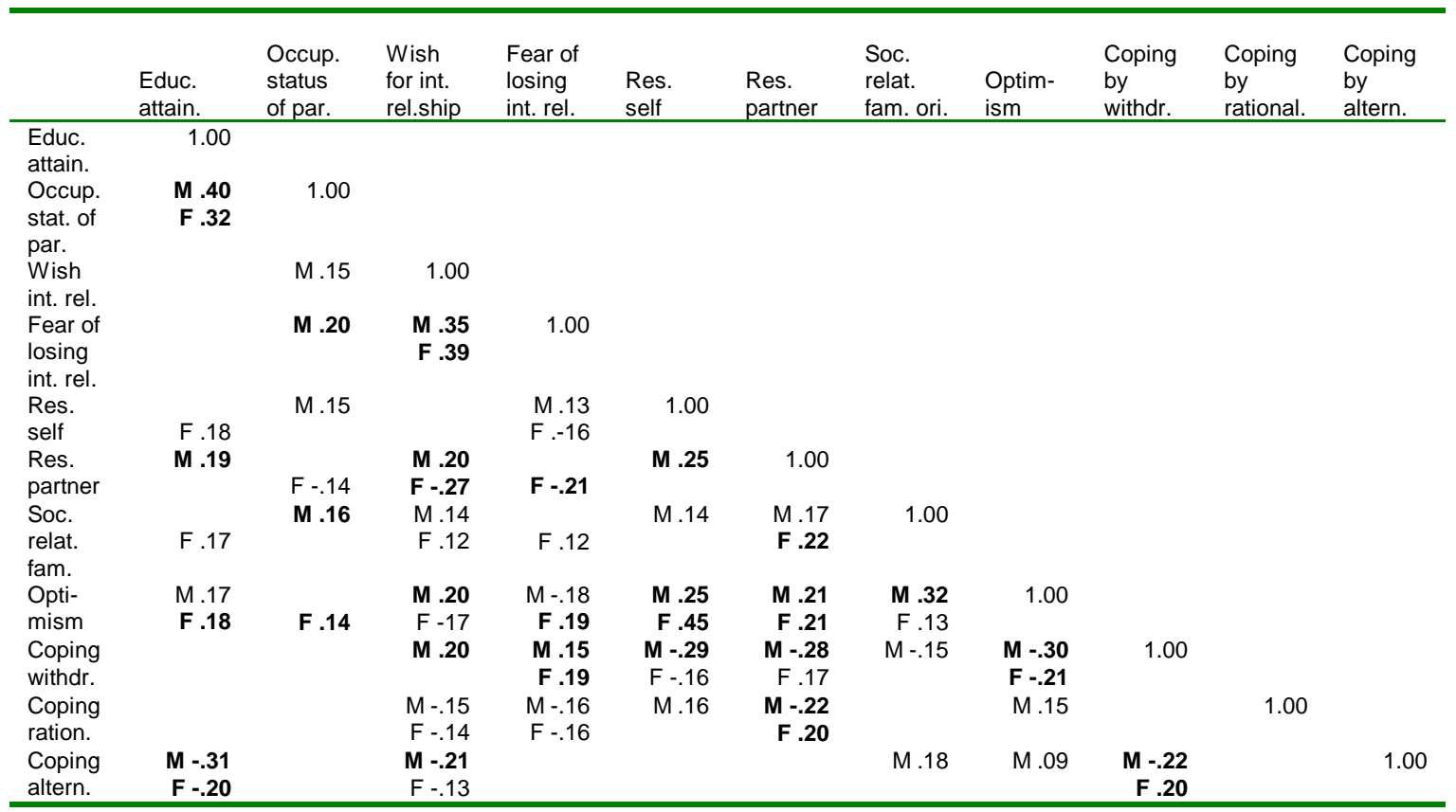

Note: $\mathrm{M}=$ men; $\mathrm{W}=$ women; Significance at 5 -percent level indicated by bold face. 
Table 13. Relative risks of first birth, by social-structural and psychological variables, controlled for age.

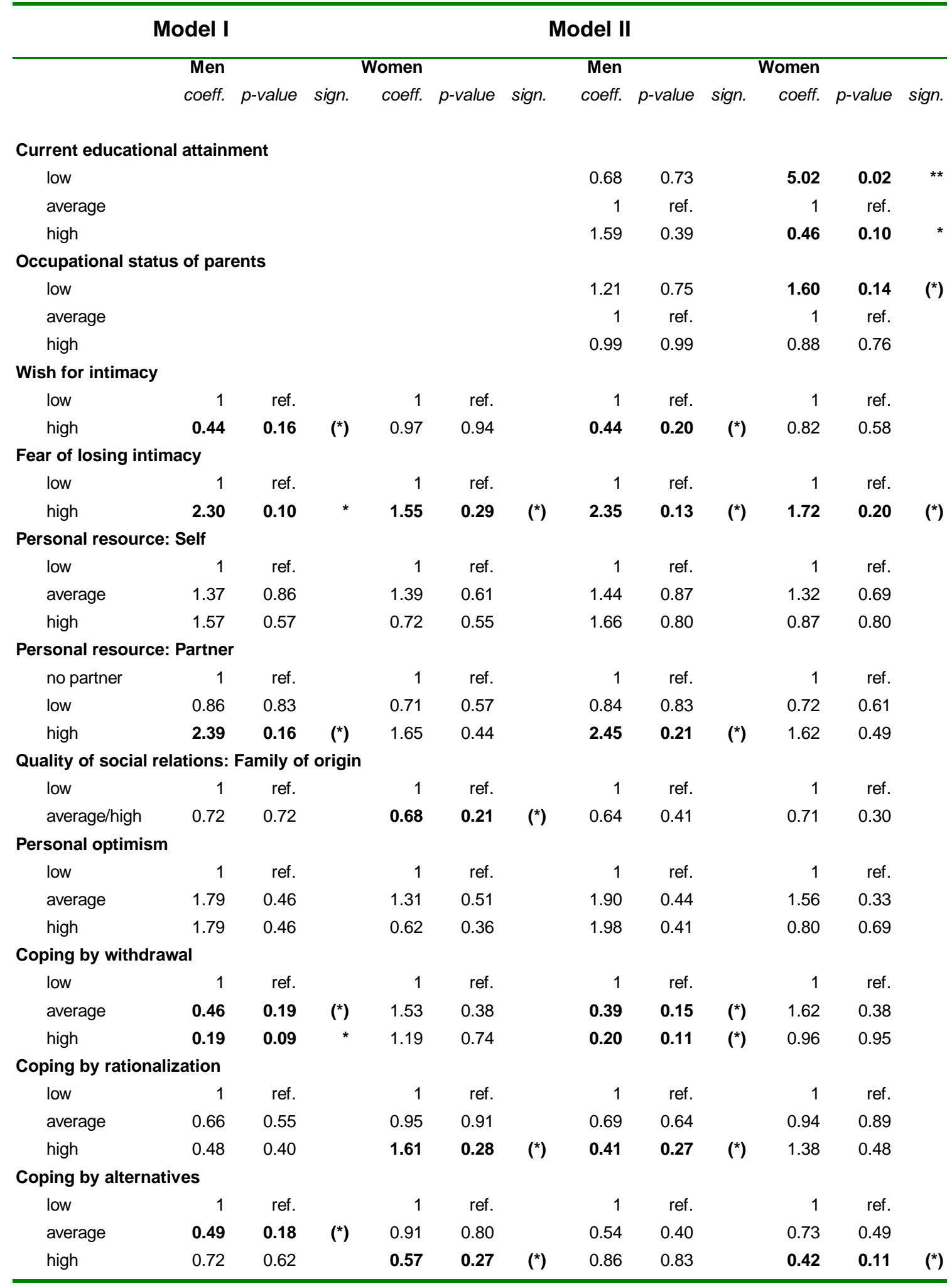

Note: Significance indicated by bold face: $* * * \mathrm{p}<0.01 ; * * \mathrm{p}<0.05 ; * \mathrm{p}<0.10 ;(*) \mathrm{p}<0.30$ 
Table 12 shows that correlations are low to weak throughout sexes, variables, and timepoints. Only for two cases, we find a correlation of $r>0.40$, namely in the cases of educational attainment and parental occupation ( $\mathrm{r}=0.40$ for men), and for optimism and self-related resources ( $\mathrm{r}=0.45$ for women).

The main results for Model I and II are displayed in Table 13. One of the immediate impressions is that various psychological factors indeed matter in explaining differential childbearing behavior in East Germany in the 1990s. Although the theoretical model and the demographic literature give a certain primacy to social-structural variables, we find clear support for the relevance of both groups of factors. In order to give a numerical documentation on these judgments, Table 14 displays in more detail to what extent the LLRT shows relevant impacts on the model fit between different models.

Table 14. Model improvement by step-wise inclusion of different clusters of variables.

\begin{tabular}{|c|c|c|c|}
\hline $\begin{array}{l}\text { Model improvement (LLRT } \\
\text { p-value) }\end{array}$ & .. the age baseline & $\begin{array}{l}\ldots \text { a model with age baseline } \\
\text { and educational variables }\end{array}$ & $\begin{array}{l}\ldots . \text { a model with age baseline } \\
\text { and personal consideration }\end{array}$ \\
\hline $\begin{array}{l}\text { Including personal } \\
\text { considerations to ... }\end{array}$ & $\begin{array}{r}\text { Men: } \mathbf{0 . 0 2 5} \\
\text { Women: } 0.117\end{array}$ & $\begin{array}{r}\text { Men: } \mathbf{0 . 0 5 3} \\
\text { Women: } 0.131\end{array}$ & - \\
\hline $\begin{array}{l}\text { Including educational } \\
\text { variables to ... }\end{array}$ & $\begin{array}{r}\text { Men: } 0.307 \\
\text { Women: } \mathbf{0 . 0 0 0}\end{array}$ & - & $\begin{array}{r}\text { Men: } 0.709 \\
\text { Women: } \mathbf{0 . 0 0 1}\end{array}$ \\
\hline
\end{tabular}

Note: P-values $<0.10$ indicated by bold face.

This table provides another interesting insight. Comparing values for women and men, it seems that for men personal considerations are more clearly relevant for understanding their transition to parenthood. LLRT-estimates for personal considerations are throughout significant, while they are not so much for women. However, for women their educational background matters significantly, whereas the LLRT for these variables does not support its relevance for men. We now go through the findings for each variable cluster.

\subsubsection{Discussion on the impact of socio-economic variables}

Aside from expected findings for sex and age as indicated in Figure 5, we find an interesting sex-specific result for the impact of educational attainment on the transition to parenthood. The initial pattern (see Section 5.3.1) of the impact of educational attainment was that of a (statistically significant) negative correlation of the education level with first-birth risks of women, and a (nearly significant) U-shaped pattern for men with higher propensities of entry into fatherhood for lowly educated and highly educated men (cf. Table 6). In addition, we found a general positive impact of a low occupational status of the parents, again with statistical significance only for women. After the 
inclusion of the psychological covariates into the model, the negative impact of the level of education and of parental-occupation status on childbearing risks of women remains intact (Model II, Table 13). For men, by contrast, a non-significant tendency of a positive impact of (increasing) educational level on childbearing risk appears.

Our findings thus indicate that a low education translate for men into behavioral traits which slow down childbearing behavior, whereas this is not the case for women. The initially observed U-shape for men is in reality a trend toward a positive correlation which is concealed by the impact of various other personal traits. In conventional demographic analyses, such characteristics are unobservable. When we control for them, we find support for the notion that education of men and women in Germany has a differential effect on their family formation (cf. Kreyenfeld 2001).

What does this finding tell us about family formation of young adults in East Germany during the 1990s? Apparently, social-structural variables are relevant for the understanding of women's fertility differentials during the post-unification period, as we expected from the literature. Women from a higher social class (i.e., those with a high education of their own or a high occupational status of their parents) have a decreased childbirth risk compared to others. This is interesting for two reasons. Firstly, it relates to findings that the impact of educational differences on women's childbearing behavior has mainly emerged after the end of socialism in transition countries (Koytcheva 2003, Kantorova 2004, Kreyenfeld 2004). Secondly, we know that the postponement of childbearing plays a crucial role in the fertility slump in East Germany during the 1990s, as elsewhere in Central and Eastern Europe. This suggests that highly educated women contributed more strongly to these developments than other women. For men, patterns appear entirely different and are more strongly related to the impact of various other personality traits.

\subsubsection{Discussion on the impact of the personal problem space}

Results for the variables which approximate people's personal problem space, that is desires for intimacy and fears of losing it, present further evidence of the character that the transition to parenthood can assume on the level of individual considerations. Whilst we did not expect very clear results for these variables, we find that their impact gain power when we also control for other covariates. We attain more statistically significant results and effects are stable regardless of whether we control only for other psychological covariates or also for the educational characteristics (Models I and II of Table 13).

It appears that for men the expression of a desire for intimacy considerably lowers the first-birth risk, but only if we control for other psychological covariates. At first glance, this is a counter-intuitive finding which requires some reflection. One interpretation can be that high values in wishes for intimacy reflect a general family orientation or 
receptiveness to the family topic, ${ }^{6}$ and that men who are more receptive to the idea of family formation may have acted particularly cautiously and responsibly concerning reproductive behavior when facing societal upheaval. Taking into account that we still find a lot of notions of male responsibility for a family in the perspective of East German men (von der Lippe and Fuhrer 2004), these men may have seen many reasons to postpone family building in the mid 1990 s. $^{7}$

The parallel finding of a positive impact of fear of losing intimacy on first-birth risks seems to support the Freudian idea that our fears belong to our strongest drives. At least with respect to the transition to parenthood, it appears that the engine of fertility is powered to a non-negligible extent by that fuel: Men and women who are particularly afraid of losing intimate relations more often opt for parenthood. Again, this impact attains significance when we control for other interwoven factors. To some extent, this finding relates to other findings that fear of loneliness in old age is an important motivation for childbearing (von Rosenstiel et al. 1986). A recently conducted qualitative study on men from our sample also reveals that fear and disapproval of remaining childless are strong concerns of childless respondents when they think about their own intentions of family formation (von der Lippe and Fuhrer 2004, von der Lippe 2005).

\subsubsection{Discussion on the impact of motivational processes}

When examining the variables that trace the potential sources of childbearing motivation back to people's resources and social relations, we find at least one impact on first-birth risks that clearly differs between women and men. Whilst most effects do not attain statistical significance, patterns in childbearing risks nevertheless give us some insight into the motivational processes for childbearing in post-unification East Germany.

Two resource variables, those of peers and family, were excluded from the final models because of their weak impact in the initial analyses. When experimentally including them into the final models we also did not find any clear effects (not shown). The perception of own abilities and of the strength and dependability of a partnership clearly outweigh the impact of friends and parents. ${ }^{8}$

\footnotetext{
6 To express a desire for intimacy will always be interwoven with many other factors like a person's current mood, recently experienced events, personal strengths and deficits, and so on. This is why in the first part of the analysis results stayed weak. The fact that results get clearer and stronger when we control for other factors shows that this comparably simple variable indeed catches a relevant impact.

${ }^{7}$ Another interpretation can be that people tend to desire what is most distant from their realization. In such a case, men who express desire for intimacy would be the more lonely ones. Table 12 with the correlations of covariates gives a different impression. For men, a desire for intimacy seems to be rather positively correlated with a resourceful partnership, whereas for women the opposite is the case. This supports our interpretation above.

${ }^{8}$ A qualitative study on East German men by von der Lippe and Fuhrer (2004) reveals that a potential start of a family is clearly perceived as a highly personal project determined by oneself and the partner, whereas other sources of influence appear irrelevant.
} 
The covariate that describes perceived resources rooted in an individual's own skills and knowledge has a somewhat different impact for the entry into parenthood of women and men. When controlling for other psychological characteristics, we find that men with high values and women with average values in this variable have the highest propensity to become a parent. Concerning the impact of resources rooted in a person's current partnership, we find a clear positive effect on first-birth risks of men and a less strong positive effect on such risks of women. This suggests that men may benefit more strongly than women from a perceived high-quality partnership as regards their transition to parenthood. For both sexes it appears slightly more unfavorable for first-birth risks to have a low-resource partnership than having no relationship at all. The impact of partner resources is unaffected by the inclusion of the other covariates into our final model. In sum, we find that for men in East Germany in the 1990s, strong personal resources are related to an increased propensity for parenthood whereas for women this pattern is not as clear.

When extending the resource covariates by an assessment of the emotional quality of social ties, we find that women and men with high quality of social relations to their family of origin have a decreased risk of entry to parenthood. However, only the result for women reaches significance. This is an unexpected finding as we expected that people may tend to reproduce good experience more readily than bad experience. At this part of the analysis we can only speculate about the reasons for our finding, but can certainly state that we do not find the expected learning effect that "a good home leads to early fertility". We speculate that people with relationship deficits of that kind may be prone to start their own family earlier in order to compensate for their negative experience or separate more clearly from their parents.

\subsubsection{Discussion on the impact of perceived action control}

Initially, we found a significantly positive effect of personal optimism on first-birth risks for men, supporting our hypothesis that a large amount of optimism was required in order to start a family in East Germany during the 1990s (see Section 5.3.2.c). For women we got the highest risks instead for those who expressed average levels of optimism. That is, women who were neither very effusive nor very desperate about their own situation had the highest propensity to become a mother. It appeared that strongly future oriented and optimistic women more often than others refrained from the earlyparenthood option, perhaps in order to pursue a career or other means of life explorations instead.

The statistical significance of these findings vanishes when we control for other covariates, but patterns remain largely the same. Note that they resemble those of the impact of self-centered personal resources on childbearing behavior. (The slight reduction in effects in Table 13 comes from the fact that the two variables are correlated 
with each other and thus measure similar traits; see Table 12). For men it appears that self reliance and general personal strength makes them more prone (attractive?) to family formation. For women, by contrast, we find a clear normalcy effect. Women with an average degree of these features in motivation and action control have a higher propensity to become a mother while the highly self reliant and self controlled group has

a reduced risk. Perhaps the latter more often are women who orient themselves toward a career in the job sphere, which we know affect the family formation of women more strongly than for men.

\subsubsection{Discussion on the impact of coping styles}

We selected three scales of individual coping styles in order to examine how habitual behavior in stressful situations may have been related to childbearing decisions in the difficult societal situation of East Germany in the 1990s (Section 5.3.2.d). For the coping styles we examine, withdrawal, rationalization, and alternatives, we find that impact patterns differ by gender. For men, we find that coping by withdrawal, that is, to give up when faced with problems, is related to a clearly reduced risk of entry into fatherhood. For women, the group with a moderate behavior on this dimension tends toward the highest childbearing propensity. This pattern is robust and even slightly clearer when we control for the other covariates in Table 13. For coping by rationalization we find that the initial sex differentials in impact patterns get stronger when we control for other covariates. Women who tend to rationalize their difficulties, that is, to persuade themselves of their simplicity, experience a higher first-birth risk than other women, whereas men with this behavior have a lower propensity to become a father. Finally, an inclination to coping by alternatives is generally related to lower first-birth risks. Being correlated with education in that coping by diversion is more typical for people with lower education (Table 12), the initial negative relation with childbearing risks becomes weaker for men and stronger for women when we control for their educational characteristics (Model II, Table 13). The remaining image is that women who tend to react to stress and demand by looking for more easily rewarding alternatives did not belong to the early mothers in East Germany in the 1990s.

In sum, we find that coping styles are related to first-birth behavior in East Germany during transition time, especially when we control for other covariates. The fact that their impact on childbearing is different for women and men requires additional consideration. It underlines that it is not sufficient to talk about general requirements for parenthood as such, but more adequate to discuss motherhood and fatherhood separately and in contrast with each other. There are different expectations, demands, and necessities for women and men with regard to parenthood in East Germany and we find this reflected in our results. 
For men's transition to fatherhood it seems decisive to not give up when faced with difficulties. Men who tend to pity themselves, hide from problems, or otherwise withdraw from burdens were not particularly likely to become a father during the postunification period. Neither were men and women who seek for an easy way out of difficult demands. These patterns are in line with our hypothesis. One surprising finding was that women who tend to rationalize stress and demands were more inclined to motherhood than other women. Apparently, seeing things through rose-colored spectacles can sometimes be purposeful behavior for women with regard to childbearing - but not so for men.

\section{Conclusion: Personal considerations and the determinants of the transition to parenthood}

Our event-history analysis of patterns in first-birth risks of young Rostockers during the 1990s yields a number of new insights into the roles of various psychological determinants of childbearing behavior. Our models provide some results that are common to the transition to fatherhood and motherhood. More interesting, however, is that so many psycho-social covariates tend to reveal contrasting effects for the familyformation behavior of men and women. We found, for example, that men who are more optimistic than others and who address difficult problems directly become fathers more early than other men. Likewise, males who are endowed with good resources rooted in their own skills and in their partnership are more likely to become fathers. For women, patterns appear quite different. For many variables we find that women with an average level of personal resources had the highest propensity to become a mother. The interpretation of the negative effect of low personal resources may be similar for women and men. More interesting is that women with high personal resources also experienced a reduced propensity to become a mother during the early post-socialist period. We take this as an indication that these women were particularly prone to pursue other arenas of life that were perhaps conceived as incompatible with (early) motherhood in the new societal context of East Germany.

We found de Bruijn's "foundation of demographic behavior" useful to inspire and structure our interdisciplinary exploration. With our new findings on how different psychological factors are related to the transition to fatherhood and motherhood we are now faced with new theoretical questions on why these patterns appear. For future research, we would find it important to consider in more detail the changing patterns in gender relations in East Germany during the 1990s and how they were interrelated with various structural and institutional changes in post-unification society. In this, we follow Eagly et al. (2000: 125) who state that "according to social role theory, the differences in the behavior of women and men that are observed in psychological studies of social behavior (...) originate in the contrasting distributions of men and women into social 
roles". In the case of family formation, we assume that such social roles instruct women and men about what they can expect from and aspire to in life, what they can expect from members of the other sex, what requirements a complex action such as starting a family involves, what different responsibilities and abilities this might involve, etc.. Thus, it is comprehensible that young adults have an increased propensity to become a parent if the quality and content of their personal considerations correspond to the (new) demands and opportunities that parenthood entails in a given societal situation. These demands and opportunities have been affected by profound institutional changes in society following German unification. Previous demographic research demonstrates how women in countries in transition have been increasingly constrained by their labor-market aspirations in childbearing behavior (Koytcheva 2003, Kantorova 2004, Kreyenfeld 2004). Nevertheless, demands and opportunities related to parenthood are not only objectively given but also subject to socially shaped perceptions in terms of gender roles. In our study, we have demonstrated how women and men in post-unification East Germany have tended to react in very gender specific modes in the way their personal considerations were related to family-formation practice.

Ultimately, we hope that our study will contribute to the general demographic research agenda on childbearing dynamics. Our investigation demonstrates how the focus on common socio-demographic determinants of childbearing behavior can fruitfully be widened - both conceptually and empirically - by broader interdisciplinary approaches (see also von der Lippe 2004, Neyer and Andersson 2004). Perhaps our fertility study can be seen as one step in the direction of what we, in a somewhat invoking tone, would label a "gender-specific psychological theory of life-course decision-making in individualized societies".

\section{Acknowledgments}

We are grateful for valuable comments from Gerda Neyer, Francesco Billari, Jan M. Hoem, Michaela Kreyenfeld, Elena Koytcheva, and two anonymous reviewers of Demographic Research. We also would like to thank Susann Backer for having edited most parts of our contribution. 


\section{References}

Ajzen, I. (1991) The theory of planned behavior. Organizational Behavior and Human Decision Processes 50: 179-211.

Bandura, A. (1986) Social Foundations of Thought and Action. A Social Cognitive Theory. Englewood Cliffs, NJ: Prentice Hall.

Bernardi, L. (2003). Channels of social influence on reproduction. Population Research and Policy Review 22 (5): 527-555.

Bronfenbrenner, U. (1981) Die Oekologie der menschlichen Entwicklung: Natuerliche und geplante Experimente. Stuttgart: Klett.

Bühler, C., and Fratczak, E. (2004) Social capital and fertility intentions: the case of Poland. MPIDR Working Paper WP-2004-012, Rostock.

Caldwell, J. C. (1982) The failure of theories of social and economic change to explain demographic change: Puzzles of modernization or westernization. Research in Population Economics 4: 297-332.

De Bruijn, B. (1999) Foundations of Demographic Theory. Choice, Process, Context. Amsterdam: Thela Thesis.

Dinkel, R. (2000) Fertilität und Mortalität als bestimmende Faktoren der Bevölkerungsentwicklung in Mecklenburg-Vorpommern. In: Bericht zu den 5. Schweriner Wissenschaftstagen. Talk available at http://www.kultusmv.de/sites/bibo/broschueren/wissenschaftstage00.pdf.

Dorbritz, J. (1997) Der demographische Wandel in Ostdeutschland - Verlauf und Erklärungsansätze. Zeitschrift für Bevölkerungswissenschaft 22(2/3): 23968.

Eagly, A.H., Wood, W., and Diekman, A. (2000) Social role theory of sex differences and similarities: A current appraisal. In: T. Eckes and H. M. Trautner (Eds.), The developmental social psychology of gender, Mahwah: Lawrence Erlbaum, pp. 123-174.

Fawcett, J.T. (Ed.) (1973) Psychological perspectives on population. New York: Basic Books.

Gollwitzer, P.M. and Bargh, J.A. (Eds.) (1996) The psychology of action: Linking cognition and motivation to behavior. New York: Guilford Press.

Heiland, F. (2004) Trends in East-West German migration from 1989 to 2002. Demographic Research 11(7): 173-194.

Huinink, J. (1995) Vergleichende Familienforschung: Ehe und Familie in der ehemaligen DDR und der Bundesrepublik Deutschland. Berlin: Max-Planck-Institut für Bildungsforschung, Arbeitsbericht Nr. 17.

Janis, L.L. and Man, L. (1977) Decision Making. A Psychological Analysis of Conflict, Choice and Commitment. New York: The Free Press.

Janke, W., Erdmann, G., and Kallus, K.W. (1997) Stressverarbeitungsfragebogen SVT, 2nd ed. Göttingen: Hogrefe.

Kantorová, V. (2004) Education and entry into motherhood: The Czech Republic during 
state socialism and the transition period (1970-1997). Demographic Research Special Collection 3(10): 245-274.

Klein, T., Niephaus, Y., Diefenbach, H., and Kopp, J. (1996) Entwicklungsperspektiven von Elternschaft und eheliche Stabilität in den neuen Bundesländern seit 1989. In: W. Bien (Ed.), Familie an der Schwelle zum neuen Jahrtausend. Wandel und Entwicklung familiarer Lebensformen, Opladen: Leske+Budrich, pp. 60-81.

Kohler, H.-P. (2000) Die Neue Demografie - Vortrag anläßlich der 5. Schweriner Wissenschaftstage zum Thema "Bevölkerungsrückgang in MecklenburgVorpommern - Katastrophe oder Chance?" MPIDR Working Paper WP2000-014, Rostock.

Koytcheva, E. (2003) Family formation before and after the transition in Bulgaria: Differences by level of education and ethnic group. Paper to the BSPS Conference, Bristol, UK.

Kreyenfeld, M. (2001) Employment and Fertility: East Germany in the 1990s. Dissertation. Rostock: Rostock University.

Kreyenfeld, M. (2003) Crisis or adaptation reconsidered: A comparison of East and West German fertility in the first six years after the 'Wende'. European Journal of Population 19: 303-329.

Kreyenfeld, M. (2004) Fertility decisions in the FRG and GDR: An analysis with data from the German Fertility and Family Survey. Demographic Research Special Collection 3(11): 275-318.

Lechner, M. (2001) The empirical analysis of East German fertility after unification: An update. European Journal of Population 17: 61-74.

Lesthaeghe, R. and Vanderhoeft, C. (2001) Ready, willing, and able: a conceptualisation of transitions to new behavioural forms. In: J.B. Casterline (Ed.), Diffusion Processes and Fertility Transition: Selected Prospectives, Committee on Population National Research Council, Washington, DC: National Academy Press, pp.240-264.

Lin, N. (2001) Social Capital: A Theory of Social Structure and Action. Cambridge: Cambridge University Press.

Luhmann, N. (1982) Liebe als Passion. Zur Codierung von Intimität. Frankfurt a.M.: Suhrkamp.

McClelland, G.H. (1983) Family-size desires as measures of demand. In: R.A. Bulatao and R.D. Lee (Eds.), Determinants of Fertility in Developing Countries, Vol. I: Supply and Demand for Children, New York: Academic Press, pp. 233-287.

Mehlan, K.-H. (1974) Auswirkungen der Legalisierung des Abortes im Bezirk Rostock (DDR). In: R. Baumann (Ed.), Das deutsche Gesundheitswesen, Berlin: Verlag Volk und Gesundheit, pp. 2216-2219. 
Meyer-Probst, B., and Teichmann, H. (1984) Risiken für die Persönlichkeitsentwicklung im Kindesalter. Leipzig: Thieme.

Miller, W.B. (1992) Personality traits and developmental experiences as antecedents of childbearing motivation. Demography 29: 265-285.

Miller, W.B. (1994) Childbearing motivations, desires, and intentions: A theoretical framework. Genetic, Social, and General Psychology Monographs 120(2): 223-258.

Miller, W.B. (1995) Childbearing motivation and its measurement. Journal of Biosocial Sciences 27: 473-487.

Miller, W.B., and Pasta, D.J. (1994) The psychology of child timing: A measurement instrument and a model. Journal of Applied Social Psychology 24: 218-250.

Neyer, G., and Andersson, G. (2004) Contemporary research on European fertility: Introduction. Demographic Research Special Collection 3(1): 1-14.

Noack, T., and Østby, L. (2001) Free to choose - but unable to stick with it? Norwegian fertility expectations and subsequent behaviour in the following 20 years. In: E. Klijzing and M. Corijn (Eds.), Brussels: Population and Family Study Centre, UN-CBGS Publication.

Reis, O. (1997) Risiken und Ressourcen der Persönlichkeitsentwicklung im Übergang zum Erwachsenenalter. Weinheim: PVU.

Reis, H.T., and Patrick, B.C. (1996) Attachment and intimacy: Component processes. In: E.T. Higgins and A.W. Kruglanski (Eds.), Social Psychology: Handbook of Basic Principles, New York: The Guilford Press, pp. 523-563.

Reis, O., Thonagel, U., Drews, F., and Meyer-Probst, B. (1996). Unterschiede zwischen mobilen und nichtmobilen jungen Ostdeutschen - Ergebnisse der Rostocker Längsschnittstudie. In: K.-U. Ettrich and M. Fries (Eds.), Lebenslange Entwicklung in sich wandelnden Zeiten, Landau: Verlag Empirische Pädagogik, pp. 384-390.

Roloff, J., and Dorbritz, J. (1999) Familienbildung in Deutschland Anfang der 90er Jahre, Opladen: Leske+Budrich.

Rotter, J.B. (1966) Generalized expectancies for internal versus external control of reinforcement. Psychological Monographs 80: 1-28.

Ryan, R.M., Sheldon, K.M., Kasser, T., and Deci, E.L. (1996) All goals are not created equal: An organismic perspective on the nature of goals and their regulation. In: P.M. Gollwitzer and J.A. Bargh (Eds.), The Psychology of Action: Linking Motivation to Behavior, New York: The Guilford Press, pp. 7-26.

Sackmann, R. (1999) Ist ein Ende der Fertilitätskrise in Ostdeutschland absehbar? Zeitschrift für Bevölkerungswissenschaft 24: 187-211.

Spielauer, M., and Houle, R. (2004). Sample size and statistical significance of hazard regression parameters. An exploration by means of Monte Carlo simulation of four transition models based on Hungarian GGS data. MPIDR Working Paper WP-2004-020, Rostock. 
Stroebe, W., and Stroebe, M. (1996) The social psychology of social support. In: E.T. Higgins and A.W. Kruglanski. (Eds.), Social Psychology: Handbook of Basic Principles. New York: The Guilford Press, pp. 597-621.

Thomson, E., and Hoem, J.M. (1998) Couple childbearing plans and births in Sweden. Demography 35: 315-322.

von der Lippe, H. (2004) Transitions to Fatherhood in East Germany in the 1990s. Psychological Determinants of Childbearing and the Meaning of Entering into Parenthood for Young Adults from Rostock: An Event-history and Qualitative Composite Investigation within the Rostock Longitudinal Survey. Magdeburg: Online Dissertation.

von der Lippe, H. (2005) Dimensionen und Determinanten des männlichen Kinderwunschs. In: A. Tölke and K. Hank. (Eds.), Männer - Das ,vernachlässigte' Geschlecht in der Familienforschung. Sonderheft 4 der Zeitschrift für Familienforschung: 44-70, Opladen: VS-Verlag

von der Lippe, H., Billari, F., and Reis, O. (2002) Bearing children in unstable times. Psychological traits and early parenthood in a lowest-low fertility context, Rostock 1990 - 1995. MPIDR Working Paper WP 2002-014, Rostock.

von der Lippe, H., and Fuhrer, U. (2004). Where qualitative research meets demography: Interdisciplinary explorations of conceptions of fatherhood in an extremely low fertility context. Qualitative Research 4(2): 201-226.

von Rosenstiel, L., Nerdinger, F.W., Oppitz, G., Spieß, E., and Stengel, M. (1986) Einführung in die Bevölkerungspsychologie. Darmstadt: Wissenschaftliche Buchgesellschaft.

Zapf, W. (1994) Die Transformation in der ehemaligen DDR und die soziologische Theorie der Modernisierung. Berliner Journal für Soziologie 4: 295-305. 